\title{
OECD Ülkelerinde Uzun Dönemli Bakım Hizmetlerinin Etkinliğinin Değerlendirilmesi
}

\section{Assessing the Efficiency of Long-Term Care Services in OECD Countries}

\author{
Şenol Demirci, ${ }^{\mathrm{a},{ }^{*}}$ Birol Yetim, ${ }^{\mathrm{b}}$ Murat Konca ${ }^{\mathrm{c}}$ \\ ${ }^{a}$ Arş. Gör., Hacettepe Üniversitesi, İİBF, Sağlık Yönetimi Bölümü, 06800, Çankaya/Ankara. \\ ORCID: 0000-0001-8552-8151

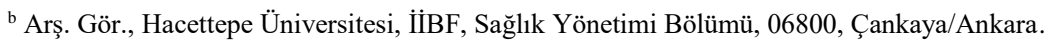 \\ ORCID: 0000-0002-1294-1874 \\ ${ }^{c}$ Arş. Gör., Hacettepe Üniversitesi, İ̈BF, Sağlık Yönetimi Bölümü, 06800, Çankaya/Ankara. \\ ORCID: 0000-0002-6830-8090
}

\section{MAKALE BILGIISI}

\section{Makale Geçmişi:}

Başvuru tarihi: 02 Eylül 2019

Düzeltme tarihi: 18 Kasım 2019

Kabul tarihi: 06 Aralık 2019

\section{Anahtar Kelimeler:}

Yaşlı Bireyler

Uzun Dönemli Bakım

Performans Değerlendirme

\section{ARTICLE INFO}

\section{Article history:}

Received: 02 September 2019

Received in revised form: 18 November 2019

Accepted 06 December 2019

\section{Keywords:}

Elderly Individuals

Long-Term Care

Performance Assessment

\section{ÖZ}

Doğumda beklenen yaşam süresinin artması ve doğurganlık hızının azalması sonucu ülkelerin yaşlı nüfus oranları artmaktadır. Kronik ve mental rahatsızlıklardan kaynaklı olarak yaşlılar uzun dönemli bakım hizmetlerinden daha fazla faydalanmaktadır. Yaşlı bireylerin uzun dönemli bakım hizmetleri kullanımının artması uzun dönemli bakımda etkinlik konusunda çalışmalar yapılmasını zorunlu kılmaktadır. Bu çalışmada, seçilmiş OECD ülkelerinin uzun dönemli bakım hizmetleri etkinlik düzeyleri 2015, 2016 ve 2017 yılları bazında Veri Zarflama Analizi (VZA), Malmquist Toplam Faktör Verimliliği Endeksi (MTFV) ve Tobit regresyon analizleri ile incelenmiş, etkinliğe etki eden değişkenler ortaya konmuş ve etkinlik ile ilgili sorun yaşayan ülkeler için önerilerde bulunulmuştur.

\section{Giriş}

Yaşanan sosyal, kültürel, ekonomik ve teknolojik gelişmelere bağlı olarak doğumda beklenen yaşam süresinin artması ve doğurganlık hızının azalması sonucu ülkelerin yaşlı nüfus oranlarında ciddi artışlar meydana gelmektedir ve bu artışlar her geçen gün katlanarak devam etmektedir (Anderson ve Hussey, 2000; Abdel-Rahman vd., 2019; Mardini vd., 2019; Sivakumar vd., 2019). Yaşlı bireyler gençlere kıyasla daha fazla ve daha pahalı sağlık hizmetleri kullanmak durumundadır (Ingle ve Nath, 2008). Bu durumun bir sonucu olarak, yakın gelecekte yaşlı nüfusun sağlık hizmetlerinin sürdürülebilirliği konusunda sorunlar yaşaması beklenmektedir (Spillman ve Lubitz, 2000). Yaşlılığın getirmiş olduğu fiziksel ve ruhsal sıkıntıların yanı sıra yaşlılarda kronik rahatsızlıkların daha sık görülmesi yaşlıların uzun dönemli bakım hizmetlerini daha fazla kullanmasına neden olmaktadır. Yaşlı bireylerin uzun dönemli bakım hizmetleri kullanımının artması uzun dönemli bakımda etkinlik konusunda çalışmalar yapılmasını

* Sorumlu yazar/Corresponding author

e-posta: senoldemrci@gmail.com 
zorunlu kılmaktadır (Björkgren vd., 2001; Wichmann vd., 2018).

Literatür incelendiğinde, uzun dönemli bakım hizmetlerinde etkinlik konusunu ele alan bazı çalışmalara rastlamak mümkündür (Ozbugday vd., 2019; Shimizutani ve Suzuki, 2001; Laine vd., 2005; Alamgir vd., 2008; Berta vd., 2010). Ancak bu çalışmaların büyük çoğunluğu ya uzun dönemli bakım merkezlerinde ya da sağlık tesislerinde yapılmıştır. Ayrıca bu çalışmaların önemli bir kısmında etkinliğin, operasyonel, klinik ya da teknik boyutlarından bir ya da birkaçına odaklanılmıştır. $\mathrm{Bu}$ nedenle, ülkeler genelinde uzun dönemli bakım hizmetlerinde etkinlik ile ilgili çalışmaların yapılmasının önemli olduğu düşünülmektedir.

$\mathrm{Bu}$ kapsamda, bu çalışmanın temel amacı, seçilmiş OECD ülkelerinin uzun dönemli bakım hizmetleri etkinlik düzeylerini incelemek ve etkinlik ile ilgili sorun yaşayan ülkeler için etkinliği artırma noktasında çözüm önerilerinde bulunmaktır.

\section{Yöntem}

$\mathrm{Bu}$ çalışmada Veri Zarflama Analizi (VZA), Malmquist Toplam Faktör Verimliliği Endeksi (MTFV) ve Tobit regresyon analizlerinden faydalanılmıştır. VZA ve MTFV analizlerinde kullanılan girdi değişkenlerini, 65 yaş üstü nüfusta kişi başına düşen uzun dönemli bakım hizmetleri harcamaları ve uzun dönemli bakım hizmetlerinde yararlanılan yatak sayısı; çıktı değişkenlerini ise, 65 yaş üstü bireylerde algılanan sağlık statüsü iyi ve çok iyi olanların oranı ve 65 yaş üstü bireylerde beklenen yaşam süresi oluşturmaktadır. Tobit regresyon analizinde bağıml değişken olarak dönüştürülmüş VZA skorlarından, bağımsız değişkenler olarak ise, VZA'da kullanılan girdi ve çıktı değişkenlerinden faydalanılmış, böylelikle OECD ülkelerinin VZA skorlarına hangi değişkenlerin etki ettiği ortaya konulmuştur. Tablo 1'de, çalışmada kullanılan değişkenlerin; kısaltmaları, veri kaynakları ve kullanım yerleri sunulmaktadır. VZA, MTFV ve Tobit regresyon analizlerine ilişkin açıklayıcı bilgiler ilerleyen başlıklarda sunulmaktadır.

\subsection{Veri Zarflama Analizi (VZA)}

VZA, karmaşık ve tanımlanması zor girdilere ve çıktılara sahip sistemlerde görece etkinlik değerlendirmelerinde sıkça faydalanılan; göreli etkinliği, kabul edilen etkinlik sınırı üzerinde bulunan karar verme birimlerine 1, diğer karar verme birimlerine 1'den düşük skorlar atayan, doğrusal programlama temeline dayalı parametrik olmayan bir analizdir (Boles vd., 1995; Laplante ve Paradi, 2015). Günümüzdeki kullanım şekli ile ilk olarak Charnes ve arkadaşları (1978) tarafindan ölçeğe göre sabit getiri (CRS) modeli olarak uygulanan VZA'nın, sonrasında Banker vd. (1984) tarafindan ölçeğe göre değişken getiri (VRS) modeli geliştirilmiştir. CRS modelinde, çıktılardaki artışın oransal olarak girdilerdeki artış ile aynı olacağı varsayılırken, VRS modelinde, çıktılardaki değişim oransal olarak girdilerdeki değişimden farklı olabilmektedir. VRS modelinde, karar verme birimlerinin büyüklükleri analiz sonuçlarına etki etmemekte, yani VRS modelinde sadece saf teknik, diğer bir deyişle yönetsel, etkinlik elde edilmektedir. Buna bağlı olarak, VRS modelinin kullanıldığı bir çalışmada etkin çıkan karar verme birimi sayısı (bu çalışmada ülkeler), CRS modeline göre daha fazladır (Banker vd., 1984). Sağlık sektörü için VRS modelinin tercih sebebi olduğu söylenebilir zira en etkin büyüklükteki ortalama etkinlik her karar verme birimi için ulaşılabilir olmayabilir (Şahin, 2008). VZA, çalışmalarında çalışmanın sonuçlarına etki eden diğer önemli bir konu ise, çalışmanın girdi odaklı mı yoksa çıktı odaklı mı olacağıdır. Sağlık sistemleri gibi, karar verme mekanizmalarında yer alanların kontrol güçlerinin çıktılardan ziyade girdiler üzerinde olduğu çalışmalarda girdi odaklı modeller benimsenmektedir (Chern ve Wan, 2000; Harris vd., 2000; Özgen ve Özcan, 2004; Şahin, 2008; Ayanoğlu vd., 2010; Özcan, 2014). Bu sebeplerden, bu çalışmada girdi odaklı VRS modeli benimsenmiştir. $\mathrm{Bu}$ modele ilişkin matematiksel formülasyon (1,2 ve 3$)$ nolu formüllerde sunulmaktadır (Banker vd., 1984):

Amaç Fonksiyonu; Max $=\sum_{r=1}^{s}\left(u_{r} y_{r j o}\right)$

Kisitlar; $\sum_{r=1}^{s}\left(u_{r} y_{r j}\right)-\sum_{j=1}^{m}\left(v_{i} x_{i j}\right) \leq$

$0 ; \sum_{i=1}^{m}\left(v_{i} x_{i j o}\right)=1$

$\mathrm{u}_{\mathrm{r}}, \mathrm{v}_{\mathrm{i}} \geq 0$

$\mathrm{r}=1, \ldots, \mathrm{s}$

$\mathrm{i}=1, \ldots, \mathrm{m}$

Yukarıdaki formülasyonda; j: çalışmada kullanılan karar verme birimlerinin sayısına, i: girdi sayısına, r: çıktı sayısına, $v_{i}$ : girdi ağırlığına $(j=1, \ldots, m), u_{r}$ : çıktı ağırlığına $(i=1, \ldots, s)$, $\mathrm{x}_{\mathrm{ij}}$ : $\mathrm{j}$. karar verme biriminin $\mathrm{i}$. girdisinin ağırlığına ve son olarak $\mathrm{y}_{\mathrm{rj}}$ : j. karar verme biriminin $r$. çıktısının ağırlığına karşılık gelmektedir.

VZA çalışmalarında girdiler ile çıktılar arasında belirli düzeyde korelasyon olması beklenirken girdilerin ve çıktıların kendi içlerinde yüksek korelasyona sahip olması istenmeyen bir durumdur ancak bu konuda referans bir aralık söz konusu değildir (Deviren ve Duran, 2018). Bu sebeple bu çalışmada, VZA öncesinde değişkenler arasındaki korelasyona da bakılmıştır.

\subsection{Malmquist Toplam Faktör Verimliliği Endeksi (MTFV)}

MTFV, Sten Malmquist (1953) tarafından önerilen modelin Caves vd. (1982a; 1982b) tarafindan VZA temelli bir analize dönüştürülmesi sonucu ortaya çıkan parametrik olmayan bir analizdir. MTFV'de karar verme birimlerinin etkinlikler hem birbirlerine hem de zamana göre değerlendirilmektedir. Bu bakımdan MTFV'nin dinamik bir analiz olduğu söylenebilir. MTFV skoru, teknik etkinlik değişimi (TED) ile teknolojik etkinlik değişimi (TD) skorlarının çarpımı sonucu elde edilir. TED ve TD değerlerinin yüksek olması karar birimi açısından yüksek ekonomik etkinliği ifade etmektedir. Üretimin ne derece etkin yapıldı ̆̆ ne şekilde değiştiği, etkinlikteki değişmelerin ne kadarının teknik gelişimden ne kadarının teknolojik gelişimden kaynaklandığı konularında bilgi sahibi olmak sağlık planlaması konusunda önemlidir. Bu sebeple her iki bileşen ile ilgili ayrı ayrı bilgi sahibi olmak önemlidir (Özcan, 2014). MTFV analizlerinde, kullanılan değişkenlere de bağlı olarak TD skoru; yatırımların ve yeni teknolojilerin, yeni sağlık hizmetlerinin ve yeni yönetim sistemlerinin sağlık sistemlerinin etkinliği üzerindeki etkisini ortaya koyarken TED skoru; bilginin, piyasadaki rekabetin, maliyet yapısının 
ve sağlık sisteminin işlevinin sağlık sistemlerinin etkinliği üzerindeki etkisini ortaya koymaktadır (Roh vd., 2011; Chowdhury vd, 2011). MTFV, TED ve TD skorları açısından iki dönem arasındaki etkinlik değişimini belirleyen sınır 1'dir. Bu skorların 1'den büyük olması etkinlikte ilerlemeyi, 1'den küçük olması gerilemeyi ve 1'e eşit olması ise durağanlığı ifade etmektedir.

Sağlık sistemlerinde etkinliğin kıyaslandığı MTFV analizlerinde, VZA'da olduğu gibi girdi odaklı modeller benimsenmektedir. Ayrıca, MTFV analizlerinde, çoğunlukla CRS modeli önerilmektedir (Grifell-tatje ve Lovell, 1996; Hoff, 2006). Bu sebeplerden, MTFV analizinde girdi odaklı CRS modeli tercih edilmiştir. $\mathrm{Bu}$ modele ilişkin matematiksel formülasyon aşağıda sunulmaktadır. (4), (5) ve (6) nolu formüllerde; $t+1$ döneminde $t$ dönemine k1yasla gerçekleşen TED, TD ve MFTV değişimi formüle edilmektedir (Caves vd., 1982a; 1982b):

$$
\begin{aligned}
& T E D=\frac{D^{t+1}\left(x_{0}^{t+1}, y_{0}^{t+1}\right)}{D^{t}\left(x_{0}^{t}, y_{0}^{t}\right)} \\
& T D=\sqrt{\left(\frac{D^{t}\left(x_{0}^{t+1}, y_{0}^{t+1}\right)}{D^{t}\left(x_{0}^{t}, y_{0}^{t}\right)}\right) \times\left(\frac{D^{t+1}\left(x_{0}^{t+1}, y_{0}^{t+1}\right)}{D^{t+1}\left(x_{0}^{t}, y_{0}^{t}\right)}\right)}
\end{aligned}
$$

$$
M T F V=\mathrm{TED} X \mathrm{TD}
$$

\subsection{Tobit Regresyon Analizi}

Literatürde VZA'dan sonra, VZA skoruna etki eden faktörlerin neler olduğunu ortaya koymak üzere, en küçük kareler regresyonu ve lojistik regresyonla birlikte en s1k kullanılan regresyon modeli Tobit regresyondur (Özcan, 2014). Tobit regresyon modeli, temeli Tobin tarafindan geliştirilen bir regresyon modeli olup, Probit modelinin bir uzantısıdır. Bu model, bağımlı değişkenin belirli bir aralıkta değer aldığı durumlarda bağımsız değişkenlerin bağıml değişken üzerindeki etkisini ortaya koymak için güçlü bir modeldir (Abbasi ve Hajihoseini, 2004). Tobit regresyon modelinin VZA'dan sonra ikinci aşama analiz olarak kullanıldığ 1 durumlarda VZA skorlarına [(1/VZA Skoru)-1] dönüşümünün uygulanması önerilmektedir zira bu şekilde normallik varsayımına yaklaşılmaktadır. Daha sonra ise analiz, soldan sifir (0) noktasında sansürlenmektedir. $\mathrm{Bu}$ durumda, oluşan Tobit regresyon modelinde bağımsız değişkenlerin etkinliğe değil, etkin olmamaya etkileri ortaya konmaktadır (Özcan, 2014). Buna bağlı olarak, Tobit regresyon analizi sonucunda istatistiki açıdan anlamlı bulunan bağımsız değişkenlerin etkinliğe etkisi ilgili bağımsız değişkenin işaretinin tersi olarak yorumlanmaktadır. Standart bir Tobit regresyon modeline ait formülasyon (7, 8 ve 9) nolu formüllerde sunulmuştur (Tobin, 1958):

$$
\begin{aligned}
& \mathrm{y}_{\mathrm{i}}^{*}=\mathrm{x}_{\mathrm{i}}^{\prime} \beta+\mathrm{u}_{\mathrm{i}}(\mathrm{i}=1, \ldots, \mathrm{n}) \\
& \mathrm{y}_{\mathrm{i}}=\left\{\begin{array}{c}
\mathrm{y}_{\mathrm{i}}^{*}, \text { lf } \mathrm{y}_{\mathrm{i}}^{*}>0 \\
0, \text { lf } \mathrm{y}_{\mathrm{i}}^{*} \leq 0
\end{array}\right. \\
& \mathrm{u}_{\mathrm{i}} \sim \operatorname{IIN}\left(0, \sigma^{-2}\right)
\end{aligned}
$$

Formülasyonda $\mathrm{y}^{*}$, pozitif ise y olarak, aksi takdirde sıfira eşit olarak gözlenen bir değişkendir. Modelin parametre vektörü $\beta \in R k$. Hata dağılımı $u_{i}$ ortalama sıfır (0) ile bağımsız normaldir ve $\sigma^{2}>0$ 'dır. Model gizli bir $\mathrm{y}^{*}$ değişkenin varlığını kabul etmektedir. $\mathrm{Bu}$ değişken $x_{i}$ açıklayıcı değişkenine $\beta$ parametreler vektörü ile bağlıdır. Bu değişkenin dağılımı normal, ortalamas $1 \mu$, varyansı $\sigma^{2}$ dir. y gözlenen değişken c keyfi sansür noktası olmak üzere model, $\mathrm{u} \sim \mathrm{N}\left(0, \sigma^{2}\right)$ ve $\mathrm{y} * \sim \mathrm{N}\left(\mu, \sigma^{2}\right)$ varsayımlarına bağlıdır (Koç ve Şahin, 2018).

Çalışma kapsamında, korelasyon, VZA ve MTFV analizleri DEA-SOLVER 13, Tobit regresyon analizi ise Eviews 9 paket programları ile yapılmıştır. Tobit regresyon modelinde güven düzeyi \%95 kabul edilmiştir.

\subsection{Kisitlilıklar ve Varsayımlar}

Çalışma kapsamında VZA ve MTFV analizlerinde, uzun dönemli bakım hizmetlerinde çalışan sağlık çalışanlarının 65 yaş ve üstü birey sayısına oranı girdi değişkeni olarak kullanılmak istenmiş, fakat bu değişken, çalışmada kapsamındaki birçok ülke için bulunamadığından çalışma kapsamından çıkarılmıştır. Bu kısıtlılık, çalışmanın önemli bir kısıdıdır. Çalışmanın diğer önemli bir kısıtlılığı ise, Türkiye de dahil olmak üzere bazı OECD ülkelerinin verilerine ulaşılamadığından bu ülkelerin çalışma kapsamından çıkarılmak zorunda kalınmasıdır. Çalışma 28 OECD ülkesi üzerinden gerçekleştirilmiştir.

Çalışmanın diğer kısıtlılıklarını ve varsayımlarını, VZA'nın ve MTFV'nin kendi kısitlılıkları ve varsayımları oluşturmaktadır. Bu analizlerin kısıtlılıkları ve varsayımları şunlardır (Narc1, 2012; Sarı, 2015):

- $\quad$ VZA ve MTFV, parametrik olmayan analizlerdir ki bu sebeple parametrik analizlerden daha az güçlüdür.

- VZA'da ve MTFV'de, aykırı değerlere sahip karar verme birimleri etkinlik sınırının bozulmasına yol açabilir; bu sebeple bu analizlerde örgütsel ve çevresel özellikleri benzer olan homojen karar verme birimleri birbirleri ile kıyaslanmalıdır.

- Elde edilen etkinlik skorları yalnızca incelenen gözlem kümesi için geçerlidir, yani farklı karar verme birimlerinin ya da değişkenlerin yer alacağ farklı çalışmalardan elde edilen etkinlik skorları ile karşılaştırma yapmak mümkün değildir.

- VZA ve MTFV sonuçlarının güvenilir olabilmesi için bu teknikleri kullanan çalışmalardaki karar verme birimlerinin toplam sayısının belirli bir sayının üstünde olması beklenmektedir. Bu sayı, ya çalışmada kullanılan girdi ve çıktı değişkenlerinin sayısının 2 katından fazla olmalı (Vassiloglou ve Giokas, 1990) ya da çalışmada kullanılan girdi ve çıktı değiş̧kenlerinin sayılarının toplamından fazla olmalıdır (Sherman, 1984). 
Tablo 1. Çalışmanın Değişkenleri

\begin{tabular}{|c|c|c|c|}
\hline Değişken & Kisaltma & Kullanım & Veri Kaynağı \\
\hline $\begin{array}{l}65 \text { yaş üstü nüfusta kişi başına düşen uzun dönemli } \\
\text { bakım hizmetleri harcaması }\end{array}$ & $\mathrm{SH}$ & $\begin{array}{l}\text { VZA'da ve MTFV'de girdi değişkeni; } \\
\text { Tobit regresyonda bağımsı değişken }\end{array}$ & OECD Health Data \\
\hline $\begin{array}{l}65 \text { yaş üstü nüfusta kişi başına düşen ve uzun dönemli } \\
\text { bakım hizmetlerinde kullanılan hastane yatak sayısı }\end{array}$ & YS & $\begin{array}{l}\text { VZA'da ve MTFV'de girdi değişkeni; } \\
\text { Tobit regresyonda bağımsız değişken }\end{array}$ & OECD Health Data \\
\hline $\begin{array}{l}65 \text { yaş üstü bireylerde algılanan sağlık statüsü iyi ve çok } \\
\text { iyi olanların oranı }\end{array}$ & SS & $\begin{array}{l}\text { VZA'da ve MTFV'de çıktı değişkeni; } \\
\text { Tobit regresyonda bağımsız değişken }\end{array}$ & OECD Health Data \\
\hline 65 yaş üstü bireylerde beklenen yaşam süresi & BYS & $\begin{array}{l}\text { VZA'da ve MTFV'de çıktı değişkeni; } \\
\text { Tobit regresyonda bağımsı değişken }\end{array}$ & OECD Health Data \\
\hline
\end{tabular}

\section{Bulgular}

Çalışma kapsamında, ilk olarak, VZA ve MTFV'de kullanılan değişkenlere ilişkin korelasyon analizi gerçekleştirilmiştir. Tablo 2 incelendiğinde, araştırma kapsamında kullanılan değişkenlerin birbirileri ile olan ilişki katsayılarının; 2015 yılı için -0,33-0,74, 2016 yılı için -0,330,72 ve 2017 y1lı için $-0,37-0,74$ aralığında olduğu görülmektedir. Buradan hareketle, girdi ve çıktı değişkenlerinin kendi içlerindeki korelasyon katsayılarının yüksek olmadığı ve buna bağlı olarak araştırmada kullanılan değişkenlerin analize uygun olduğu sonucuna ulaşılmıştır.

Tablo 2. Değişkenler Arası Korelasyon Analizi Sonuçları

\begin{tabular}{|c|c|c|c|c|}
\hline \multicolumn{5}{|c|}{2015} \\
\hline & SH & YS & SS & BYS \\
\hline SH & 1 & & & \\
\hline YS & $-0,30$ & 1 & & \\
\hline SS & 0,74 & $-0,33$ & 1 & \\
\hline BYS & 0,54 & $-0,05$ & 0,68 & 1 \\
\hline \multicolumn{5}{|c|}{2016} \\
\hline & SH & YS & SS & BYS \\
\hline SH & 1 & & & \\
\hline YS & $-0,28$ & 1 & & \\
\hline SS & 0,72 & $-0,33$ & 1 & \\
\hline BYS & 0,50 & $-0,05$ & 0,64 & 1 \\
\hline \multicolumn{5}{|c|}{2017} \\
\hline & SH & YS & SS & BYS \\
\hline SH & 1 & & & \\
\hline YS & $-0,28$ & 1 & & \\
\hline SS & 0,74 & $-0,37$ & 1 & \\
\hline BYS & 0,53 & $-0,02$ & 0,67 & 1 \\
\hline
\end{tabular}

Tablo 3'te, VZA'nın girdi odaklı VRS Modeline göre sonuçlar yer almaktadır. Buna göre, çalışma kapsamındaki ülkelerin; 2015 yılında \%46'sı, 2016 ve 2017 yıllarında \%43'ü etkin bulunmuştur. Çalışmanın kapsadığı tüm y1llarda etkin bulunan ülkeler; Kanada, Fransa, Yunanistan, İtalya, Lüksemburg, Norveç, Polonya, Slovakya, İspanya, İsviçre ve ABD olup bu ülkelerin çalışma kapsamındaki tüm ülkeler içerisindeki oranı \%39'dur. Tüm yıllarda etkin bulunan ülkelerin çıktı değişkenleri incelendiğinde, bu ülkelerde yaşayan 65 yaş üstü bireyler için beklenen yaşam süresinin ve bu bireyler arasında sağlık statüsü iyi ve çok iyi olanların oranının görece yüksek olduğu görülmektedir. Bu sebeple bu ülkelerin tüm yillarda etkin bulunduğu söylenebilir. Çekya, çalışmanın kapsadığı tüm yıllarda en düşük etkinlik skoruna sahip ülke konumundadır. Çekya'nın, özellikle YS değişkeni bakımından nispeten yüksek girdi kullanması fakat çıktı değişkenlerinde görece çok düşük istatistiklere sahip olması, çalışma kapsamındaki tüm yıllarda en düşük etkinlik skoruna sahip ülke olmasını açıklamaktadır. Çalışma kapsamındaki ülkelerin etkinlik skorları ortalamalarının; 2015 yılında $0,784 \pm 0,260,2016$ y1lında $0,744 \pm 0,291$ ve 2017 yilında $0,764 \pm 0,265$ olduğu görülmektedir.

Tablo 3. Girdi Odaklı VRS Modeli Sonuçları

\begin{tabular}{lccc}
\hline Ülkeler & $\mathbf{2 0 1 5}$ & $\mathbf{2 0 1 6}$ & $\mathbf{2 0 1 7}$ \\
\hline Avusturya & 0,369 & 0,351 & 0,344 \\
Belçika & 0,714 & 0,737 & 0,724 \\
Kanada & 1 & 1 & 1 \\
Çek Cumhuriyeti & 0,206 & 0,171 & 0,172 \\
Danimarka & 1 & 0,981 & 0,916 \\
Estonya & 0,548 & 0,432 & 0,449 \\
Finlandiya & 0,349 & 0,324 & 0,454 \\
Fransa & 1 & 1 & 1 \\
Almanya & 0,964 & 0,924 & 1 \\
Yunanistan & 1 & 1 & 1 \\
Macaristan & 0,511 & 0,415 & 0,438 \\
İzlanda & 0,695 & 0,475 & 0,560 \\
İrlanda & 0,713 & 0,686 & 0,780 \\
İsrail & 1 & 1 & 0,922 \\
İtalya & 1 & 1 & 1 \\
Güney Kore & 0,494 & 0,234 & 0,458 \\
Letonya & 0,780 & 0,667 & 0,682 \\
Litvanya & 0,484 & 0,449 & 0,471 \\
Lüksemburg & 1 & 1 & 1 \\
Hollanda & 0,412 & 0,435 & 0,454 \\
Norveç & 1 & 1 & 1 \\
Polonya & 1 & 1 & 1 \\
Slovakya & 1 & 1 & 1 \\
Slovenya & 0,964 & 0,895 & 0,902 \\
İspanya & 1 & 1 & 1 \\
İsveç & 0,748 & 0,667 & 0,654 \\
İsviçre & 1 & 1 & 1 \\
ABD & 1 & 1 & 1 \\
Ortalama & $\mathbf{0 , 7 8 4}$ & $\mathbf{0 , 7 4 4}$ & $\mathbf{0 , 7 6 4}$ \\
Standart Sapma & $\mathbf{0 , 2 6 0}$ & $\mathbf{0 , 2 9 1}$ & $\mathbf{0 , 2 6 5}$ \\
\hline
\end{tabular}

Tablo 4'te, etkin bulunan ülkelerin etkin bulunmayan ülkelere referans gösterilme sayıları sunulmaktadır. Buna göre, etkin bulunmayan ülkelere en fazla referans gösterilen ülkeler; 2015 ve 2016 yıllarında Polonya, 2017 yılında ise Yunanistan ve Amerika Birleşik Devletleri (ABD)'dir. Fransa, çalışma kapsamındaki üç yılda da etkin bulunmasına rağmen, etkin bulunmayan herhangi bir ülkeye referans gösterilmemiştir. $\mathrm{Bu}$ noktada dikkat edilmesi gereken önemli bir husus, VZA'da fazlaca referans gösterilen etkin ülkelerin, etkin bulunmayan ülkelere benzer girdi ve çıktı bileşimlerine sahip oldukları için fazlaca referans gösterilmeleridir. Buradan hareketle, Polonya, Yunanistan ve ABD'nin bu çalışmada kullanılan girdiler ve çıktılar bakımından etkin bulunmayan ülkelere yakın göstergelere sahip oldukları için en fazla referans gösterilen ülkeler olduğu yorumu yapılabilir. 
Tablo 4. Etkin Bulunan Ülkelerin Yıllara Göre Referans Gösterilme Sayıları

\begin{tabular}{lccc}
\hline Ülkeler/Yıllar & $\mathbf{2 0 1 5}$ & $\mathbf{2 0 1 6}$ & $\mathbf{2 0 1 7}$ \\
\hline Kanada & 1 & 0 & 1 \\
Danimarka & 1 & - & - \\
Fransa & 0 & 0 & 0 \\
Almanya & - & - & 0 \\
Yunanistan & 6 & 10 & $\mathbf{1 0}$ \\
İsrail & 0 & 0 & - \\
İtalya & 5 & 5 & 8 \\
Lüksemburg & 5 & 6 & 3 \\
Norveç & 3 & 4 & 5 \\
Polanya & $\mathbf{1 0}$ & $\mathbf{1 2}$ & 7 \\
Slovakya & 5 & 0 & 1 \\
İspanya & 2 & 1 & 3 \\
İsviçre & 2 & 1 & 2 \\
ABD & 8 & 9 & $\mathbf{1 0}$ \\
\hline
\end{tabular}

Çalışma kapsamında, VZA'da kullanılan değişkenlerin bağımsız değişkenler, 2015, 2016 ve 2017 yıllarına ait dönüşümlü VZA skorlarının ise bağımlı değişken olduğu, soldan sıfir noktasında sansürlü bir Panel Tobit regresyon modeli kurulmuş ve sonuçlar Tablo 5 'te sunulmuştur. Buna göre SH ve YS değişkenlerindeki artışlar, etkin olmamayı artırırken, BYS değişkenindeki artış, etkinliği artırmaktadır $(\mathrm{p}<0,05)$. Elde edilen sonuçların makul olduğu görülmektedir zira girdileri kısarak çıktıları artırmak etkinliğe olumlu etki edecektir.

Tablo 5. Panel Tobit Regresyon Analizi Sonuçları

\begin{tabular}{cccc}
\hline Değişken & Katsayı & Standart Hata & $\mathrm{p}$ \\
\hline DBYB & $\mathbf{- 0 , 5 1 8 8 2 2}$ & $\mathbf{0 , 1 6 2 8 6 7}$ & $\mathbf{0 , 0 0 1 4}$ \\
SS & $-0,014703$ & 0,015130 & 0,3312 \\
YS & $\mathbf{0 , 1 0 6 4 2 4}$ & $\mathbf{0 , 0 2 3 2 5 1}$ & $\mathbf{0 , 0 0 0 0}$ \\
SH & $\mathbf{0 , 0 0 1 6 6 0}$ & $\mathbf{0 , 0 0 0 5 3 5}$ & $\mathbf{0 , 0 0 1 9}$ \\
C & 9,424125 & 2,745098 & 0,0006 \\
\hline Avg, log likelihood & $-1,155505$ & Log likelihood & $-94,4625$ \\
Soldan Sansürlü & & Sağdan Sansürlü & \\
Gözlem & 37 & Gözlem & 0 \\
Sansürsüz Gözlem & 47 & Toplam Gözlem & 84 \\
\hline
\end{tabular}

Tablo 6'da MTFV analizi sonuçlarına göre ülke skorları gösterilmektedir. MTFV skorlarına göre; Finlandiya, İtalya, Hollanda ve Slovenya tüm dönemlerde bir önceki döneme kıyasla etkinlik ilerlemesi sağlamıştır.

2016 yılında 2015 yılına kıyasla çalışma kapsamındaki ülkelerin uzun dönemli bakım hizmetleri performansı etkinlik bakımından ortalama olarak \%0,4'lük küçük bir ilerleme sağlamıştır. Söz konusu ilerlemeyi sağlayan etmen TD değerinde yaşanan artıştır zira ilgili dönemde TED değeri düşüş göstermiştir. Bu dönemde etkinlik açısından en fazla ilerlemeyi \%60'lık etkinlik artışı ile Yunanistan gerçekleştirmiştir. Yunanistan'ın hem TED hem de TD değerleri, bu dönemde yaklaşık \%26’lık artış göstermiştir. MTFV analizlerinde, kullanılan değişkenlere de bağlı olarak, TD değeri; alt ve üst yapı yatırımlarının, teknolojik gelişmelerin, yönetim anlayışındaki reformların etkinlik üzerindeki etkisini ortaya koyarken TED değeri; rekabetin, maliyet yapısının ve sağlık sisteminin işlevinin sağlık sistemlerinin etkinliği üzerindeki etkisini ortaya koymaktadır. Buradan hareketle, 2015-2016 döneminde Yunanistan'ın, uzun dönemli bakım hizmetlerini sunarken maliyetlerini kısarak bu alanda daha az harcama yaptığı, buna rağmen bu ülkede yaşayan 65 yaş üstü bireylerde algılanan sağlık statüsünün ve 65 yaş üstü beklenen yaşam süresinin bu azalışlardan ciddi şekilde etkilenmediği söylenebilir. Yunanistan'ın 2008 küresel krizi ile birlikte ekonomik olarak gerilemesi, yaptığ 1 harcamalar konusunda dikkatli davranmasına sebep olmuştur ki bu nedene bağlı olarak Yunanistan'ın bu çalışmada, 2015-2016 döneminde uzun dönemli bakım hizmetlerinde en fazla etkinlik ilerlemesi sağlayan ülke olduğu düşünülmektedir.

2015-2016 döneminde en fazla gerileme gösteren ülke, yaklaşık \%30'luk etkinlik gerilemesi ile Slovakya olmuştur. Slovakya, her ne kadar VZA'da tüm yillarda etkin bulunmuş olsa da; VZA statik, MTFV dinamik birer analiz olduğundan Slovakya'nın yıllar arası geçişlerde etkinliği sağlamada beklenenin gerisinde kaldığ $\breve{1}_{1}$ yorumu yapılabilir. Slovakya'nın 2015-2016 dönemine ilişkin uzun dönemli bakım hizmetleri etkinliği incelendiğinde, bu ülkenin TD değerinde yaklaşık \%36'lık etkinlik ilerlemesi sağlarken TED değerinde yaklaşık \%48'lik etkinlik gerilemesi yaşadığ1 görülmektedir. Bu bulgudan Slovakya'nın, uzun dönemli bakımın etkin bir şekilde sunulmasına ilişkin atması gereken adımların, 65 yaş üstü bireylerde algılanan sağlık statüsü oranlarını artırması ve gereksiz harcamalardan kaçınarak maliyetlerini azaltması olduğu söylenebilir.

2016-2017 dönemi incelendiğinde, 2017 yılında 2016 yılına kıyasla çalışma kapsamındaki ülkelerin uzun dönemli bakım hizmetleri performansı etkinlik bakımından ortalama olarak \%0,4'lük küçük bir gerileme göstermiştir. Bahse konu gerilemenin sebebi, TD değerinde yaşanan düşüştür; bu dönemde her ne kadar TED değeri artış gösterse de bu artış MTFV değerini 1'in üzerine çıkarmaya yetmemiştir. 20162017 döneminde MTFV değeri bakımından en fazla etkinlik ilerlemesini İsviçre göstermiştir. İsviçre'nin uzun dönemli bakım hizmetlerinde, 2017 yılında 2016 yılına kıyasla yaklaşık \%29'luk etkinlik ilerlemesi sağladığı görülmektedir. $\mathrm{Bu}$ çalışmada çıktı olarak kullanılan değişkenler açısından bakıldığında, İsviçre'nin 2016-2017 döneminde 65 yaş üstü bireylerde algılanan sağlı statüsü seviyesini artırdığı görülmektedir ki bunun MTFV değerinde artış sağladığı düşünülmektedir. Bu bulgu, İsviçre'nin TED ve TD değerlerindeki değişimle uyumludur. 2016-2017 döneminde İsviçre, TED değerinde ilerleme, TD değerinde ise gerileme göstermiştir. Yani İsviçre'nin, 65 yaş üstü bireylerde algılanan sağlık statüsü seviyesi ve 65 yaş üstü yaşam beklentisi konularında görece yüksek değerlere sahip olmasına rağmen, bu konularda bazı atıl harcamaları olduğu yorumu yapılabilir.

2016-2017 döneminde MTFV değeri bakımından en fazla etkinlik gerilemesini İsrail göstermiştir. İsrail'in VZA skorları incelendiğinde, bu ülkenin 2016 yılında etkin 2017 yılında ise etkin olmadığı görülmektedir. 2016-2017 döneminde İsrail hem TED hem de TD değerinde gerileme göstermiştir ki bu durumun bir sonucu olarak MTFV değeri 1 'in altında kalmıştır. İsrail'in bu çalışmada kullanılan değişkenlerine ait istatistikleri incelendiğinde, $\mathrm{SH}$ ve YS değişkenlerinde artış ve 65 yaş üstü bireylerin algılanan sağlık statüsü seviyelerinde azalış yaşadığı görülmektedir. İsrail'in girdilerini artırırken çıktılarından birinde, ciddi sayılabilecek bir düşüş yaşaması, hem TED hem de TD değerlerinde gerileme yaşamasına sebep olmuş ve buna bağlı olarak MTFV değeri gerileme göstermiştir.

Çalışma kapsamında, son olarak, 2017 yılında 2015 yılına göre ülkelerin uzun dönemli bakım hizmetlerinin etkinliği, 2 
yıllık dönem bazında incelenmiștir. Bulgulara göre, bu dönemde ülkelerin uzun dönemli bakım hizmetleri performans1 etkinlik bakımından ortalama olarak $\% 0,5$ 'lik küçük bir gerileme göstermiştir. Bu dönemde TD değerinde ortalama olarak bir ilerleme yaşansa da bu ilerleme, TED değerinde yaşanan ortalama gerilemeyi telafi etmeye yetmemiştir. 2015-2017 döneminde MTFV değeri bakımından en fazla ilerleme gösteren ülke, \%42'lik etkinlik ilerlemesi ile İtalya olmuştur. İlgili dönemde İtalya hem TED hem de TD değerlerinde ilerleme göstermiştir. 2015-2017 döneminde İtalya YS değişkeninde azaltmaya gitmesine rağmen, 65 yaş üstü bireylerde algılanan sağlık statüsü seviyesinde ciddi artışlar sağlamıştır. $\mathrm{Bu}$ durumun bir sonucu olarak İtalya, uzun dönemli bakım hizmetlerinin etkinliğinde 2015-2017 döneminde en fazla ilerleme kaydeden ülke olmuştur.
2015-2017 döneminde etkinlik bakımından en fazla gerilemeyi, 2016-2017 döneminde olduğu gibi İsrail yaşamıştır. 2016-2017 dönemi için İsrail özelinde yapılan yorumlar 2015-2017 dönemi için de yapılabilir ancak burada dikkat edilmesi gereken nokta, 2016-2017 döneminde hem TED hem de TD değerlerinde gerileme yaşayan İsrail'in 2015-2017 döneminde TD değerinde ilerleme göstermesidir. İsrail'in TD değerinde 2015-2017 dönemi için gösterdiği etkinlik ilerlemesi, bu çalıșmada girdi olarak kullanılan SH ve YS değişkenlerinin 2017 yılında 2015 yılına kıyasla sadece küçük çaplı bir artış göstermesi ile açıklanabilir. 2015-2017 döneminde SH ve YS değişkenlerinde görülen bu artışlar, aynı değişkenler için diğer ülkelerde çoğunlukla daha yüksek olduğundan, MTFV analizi İsrail'i, görece olumlu değerlendirmiştir.

Tablo 6. MTFV Endeks Sonuçları

\begin{tabular}{|c|c|c|c|c|c|c|c|c|c|}
\hline \multirow{2}{*}{ Ülkeler/Dönemler } & \multicolumn{3}{|c|}{$2015=>2016$} & \multicolumn{3}{|c|}{$2016=>2017$} & \multicolumn{3}{|c|}{$2015=>2017$} \\
\hline & TED & TD & MTFV & TED & TD & MTFV & TED & TD & MTFV \\
\hline Avusturya & 0,918 & 1,094 & 1,005 & 0,986 & 0,978 & 0,965 & 0,906 & 1,071 & 0,970 \\
\hline Belçika & 0,849 & 1,181 & 1,003 & 1,058 & 0,924 & 0,977 & 0,898 & 1,093 & 0,982 \\
\hline Kanada & 0,902 & 1,100 & 0,993 & 1,022 & 0,974 & 0,995 & 0,922 & 1,073 & 0,989 \\
\hline Çek Cumhuriyeti & 0,863 & 1,161 & 1,002 & 1,022 & 0,943 & 0,963 & 0,882 & 1,090 & 0,961 \\
\hline Danimarka & 0,937 & 0,996 & 0,933 & 0,980 & 1,004 & 0,984 & 0,918 & 0,988 & 0,907 \\
\hline Estonya & 0,730 & 1,285 & 0,938 & 1,059 & 0,941 & 0,997 & 0,773 & 1,176 & 0,909 \\
\hline Finlandiya & 0,929 & 1,088 & 1,011 & 1,236 & 0,974 & 1,203 & 1,148 & 1,072 & 1,231 \\
\hline Fransa & 0,833 & 1,103 & 0,918 & 1,051 & 0,972 & 1,022 & 0,875 & 1,073 & 0,939 \\
\hline Almanya & 0,997 & 0,967 & 0,964 & 0,942 & 1,011 & 0,953 & 0,939 & 0,987 & 0,927 \\
\hline Yunanistan & 1,264 & 1,268 & 1,602 & 0,915 & 0,922 & 0,843 & 1,156 & 1,152 & 1,332 \\
\hline Macaristan & 0,829 & 1,259 & 1,044 & 1,069 & 0,893 & 0,955 & 0,886 & 1,145 & 1,015 \\
\hline İzlanda & 0,882 & 1,107 & 0,977 & 0,983 & 0,971 & 0,955 & 0,867 & 1,074 & 0,931 \\
\hline İrlanda & 0,841 & 1,145 & 0,964 & 1,067 & 0,947 & 1,010 & 0,897 & 1,084 & 0,973 \\
\hline İsrail & 0,824 & 1,218 & 1,003 & 0,745 & 0,911 & 0,679 & 0,614 & 1,111 & 0,682 \\
\hline İtalya & 1,120 & 1,120 & 1,254 & 1,179 & 0,959 & 1,131 & 1,320 & 1,078 & 1,423 \\
\hline Güney Kore & 0,852 & 1,117 & 0,952 & 1,068 & $\mathbf{0 , 8 8 7}$ & 0,948 & 0,911 & 1,028 & 0,936 \\
\hline Letonya & 0,750 & 1,330 & 0,997 & 1,054 & 0,939 & 0,990 & 0,791 & 1,207 & 0,954 \\
\hline Litvanya & 1,005 & 0,974 & 0,979 & 1,060 & 0,893 & 0,946 & 1,065 & 0,870 & 0,927 \\
\hline Lüksemburg & 0,936 & 1,008 & 0,944 & 1,078 & 0,979 & 1,055 & 1,009 & 0,985 & 0,994 \\
\hline Hollanda & 0,952 & 1,134 & 1,080 & 1,055 & 0,949 & 1,001 & 1,005 & 1,082 & 1,087 \\
\hline Norveç & 1,026 & 0,970 & 0,996 & 0,978 & 1,025 & 1,002 & 1,004 & 0,990 & 0,993 \\
\hline Polonya & 0,974 & 1,087 & 1,059 & 0,932 & 0,919 & 0,857 & 0,908 & 1,032 & 0,936 \\
\hline Slovakya & 0,516 & 1,364 & 0,703 & 1,188 & 0,929 & 1,104 & 0,613 & 1,261 & 0,773 \\
\hline Slovenya & 0,939 & 1,106 & 1,038 & 1,074 & 0,970 & 1,041 & 1,008 & 1,074 & 1,083 \\
\hline İspanya & 0,919 & 1,082 & 0,994 & 1,065 & 0,986 & 1,050 & 0,979 & 1,068 & 1,045 \\
\hline İsveç & 0,799 & 1,172 & 0,936 & 1,047 & 0,930 & 0,974 & 0,836 & 1,091 & 0,912 \\
\hline İsviçre & 0,724 & 1,168 & 0,846 & 1,392 & 0,930 & 1,294 & 1,008 & 1,092 & 1,101 \\
\hline $\mathrm{ABD}$ & 0,738 & 1,315 & 0,971 & 1,021 & 0,965 & 0,985 & 0,754 & 1,240 & 0,935 \\
\hline Ortalama & 0,881 & 1,140 & 1,004 & 1,047 & 0,951 & 0,996 & 0,925 & 1,080 & 0,995 \\
\hline Maksimum & 1,264 & 1,364 & 1,602 & 1,392 & 1,025 & 1,294 & 1,320 & 1,261 & 1,423 \\
\hline Minimum & 0,516 & 0,967 & 0,703 & 0,745 & $\mathbf{0 , 8 8 7}$ & 0,679 & 0,613 & $\mathbf{0 , 8 7 0}$ & 0,682 \\
\hline Standart Sapma & $\mathbf{0 , 1 3 9}$ & 0,109 & 0,147 & $\mathbf{0 , 1 1 3}$ & $\mathbf{0 , 0 3 5}$ & $\mathbf{0 , 1 1 0}$ & 0,149 & $\mathbf{0 , 0 8 1}$ & 0,147 \\
\hline
\end{tabular}




\section{Tartışma ve Sonuç}

Daha uzun yaşam beklentisi ve doğurganlık oranlarındaki azalış sebebiyle OECD ülkelerindeki yaşlı nüfus oranı giderek artmaktadır. OECD ülkelerinde, 65 yaşın üzerindeki nüfusun pay1 1960 'ta ortalama olarak \%9'dan az iken 2015 'te bu oran $\% 17$ 'ye yükselmiștir ve 2050 'de $\% 28$ 'e ulaşması beklenmektedir. OECD ülkelerinin üçte ikisinden fazlasında, 2050 yılına kadar nüfusun en az dörtte birinin 65 yaşın üzerinde olacağı tahmin edilmektedir (OECD, 2017). Nüfusun yaşlanmasıyla birlikte kronik ve mental rahatsızlıklar gibi uzun dönemli bakım gerektiren bazı rahatsızlıklara sahip bireylerin sayısında ciddi artışlar meydana gelmektedir. Bu durumun sonucu olarak da uzun dönemli bakıma ihtiyaç duyulmaktadır. Uzun dönemli bakıma olan talep, genellikle yaşla ilişkili olup daha çok 65 yaş ve üstündeki bireyler uzun dönemli bakım talep etmektedir (Colombo vd., 2011).

OECD ülkelerinin 2015, 2016 ve 2017 yıllarına ait 65 yaş ve üzeri uzun dönemli bakım hizmetlerinin etkinliğinin değerlendirildiği bu çalışmada, VZA, MTFV ve Tobit Regresyon analizlerinden faydalanılmıştır. Literatür incelendiğinde, bu analizleri kullanarak ülke sağlık sistemlerinin etkinliklerini değerlendiren çeşitli çalışmalar mevcuttur (Spinks ve Hollingsworth, 2009; Moreno-Serra ve Smith, 2012; Samut ve Cafri, 2016; Özcan ve Khushalani, 2017).

Ozbugday ve diğerleri (2019) tarafindan uzun dönemli bakım tesislerinde hizmet alan bireylerin çıtı ve uzun dönemli bakım harcaması ve yatak sayısının girdi değişkeni olarak alındığı 17 OECD ülkesinin 2009-2014 yılları arası uzun dönemli bakımının VZA ile değerlendirildiği çalışmada; Estonya, Macaristan, Japonya, Polonya, Slovakya ve ABD ülkeleri tüm yıllarda etkin bulunmuştur. $\mathrm{Bu}$ çalışmada, VZA sonuçlarına göre, Kanada, Fransa, Yunanistan, İtalya, Lüksemburg, Norveç, Polonya, Slovakya, İspanya, İsviçre ve ABD tüm yıllarda etkin bulunmuştur. Bu ülkeler arasında Yunanistan, Polonya ve $\mathrm{ABD}$ en fazla referans gösterilen ülkelerdir. Etkin bulunmayan ülkeler açısından bu ülkeler örnek alınabilir.

VZA'dan sonra ikinci aşama analiz olarak, VZA'da kullanılan değişkenlerin bağımsız değişkenler, 2015, 2016 ve 2017 yıllarına ait dönüşümlü VZA skorlarının ise bağımlı değişken olarak alındığ 1 bir Tobit regresyon modeli kurulmuştur. Analiz neticesinde BYS, YS ve SH değişkenleri sonuçları istatistiki açıdan anlamlı bulunmuştur. Etkinlik ile BYS arasında doğru, YS ve SH arasında ise ters orant1 mevcuttur. Tobit regresyon analizinde yer alan ve istatistiki açıdan anlamlı bir şekilde VZA skoruna etki eden değişsenler arasında en büyük katsayının BYS değişkenine ait olduğu görülmektedir. BYS, sadece uzun dönemli bakım hizmetlerinin bir sonucu değildir; gelir, eğitim durumu, fiziki ve sosyokültürel çevre vb. faktörler de BYS üzerinde etki sahibidir (OECD, 2015). Bu sebeple uzun dönemli bakım hizmetlerinin etkinliğini artırmak isteyen ülkeler, sayılan faktörlerde de iyileştirmeler veya dönüşümler yapmalıdır. Tobit regresyon analizine göre, YS azaldıkça etkinlik artmaktadır. Uzun dönemli bakımda YS'nin azaltılabilmesini sağlamak için özellikle yaşlı bireylere evlerinde aile bireyleri ve sağlık profesyonelleri tarafindan bakım sunulabilir. Yaşlı bireyin aile desteğini alması ve hizmet sunum şekli gibi nedenler dolayısıyla uzun dönemli bakımın evde sunulması bireyin sağlık sonuçlarını daha olumlu etkileyebilmektedir (OECD/European Commission, 2013). Bu çalışmada elde edilen diğer önemli bir bulgu, sağlık harcaması azaldıkça etkinliğin artmasıdır. Bu noktada RAI (Resident Assessment Instrument) uzun dönemli bakım harcamalarının daha uygun seviyelere çekilmesine yarar sağlayabilecek önemli bir araç olabilir. RAI, yaşlı bireylerin yaşam kalitesini artırmak için interRAI tarafindan geliştirilen, sürekli ve kapsamlı bir klinik değerlendirme araçları paketidir. Bu paket içerisinde yer alan uzun dönemli bakımın değerlendirilmesini sağlayan interRAI LTCF (Long-Term Care Facility), uzun dönemli bakım alan bireyleri bakım noktasında değerlendirmek, risk durumlarını ortaya çıkarmak, bakım planları hazırlamak, ödeme seviyelerini belirlemek, süreçleri değerlendirmek ve gerçek zamanlı elektronik raporlar üretmek için kullanılmaktadır (Smith vd., 2009). Özellikle uzun dönemli bakım harcamalarına etkisi açısından interRAI LTCF aracından elde edilen bilgiler sayesinde uzun dönemli bakım alan bireylerin bakım maliyetlerini belirleyecek vaka-karmaları oluşturulmaktadır. Vaka-karmaları sayesinde farklı ihtiyaçları olan bireylere yönelik bakım maliyetleri belirlenmekte ve kişiye özel olarak kaynak tahsisleri gerçekleştirilmektedir (interRAI, 2019).

Bu çalışmada karar verme birimlerinin etkinliklerinin yıllara göre nasıl değiştiğini belirlemek için VZA temelli bir analiz olan MTFV'den faydalanılmıştır. VZA, statik bir analizdir, yani VZA'da karar verme birimlerinin etkinlikleri hakkında sadece karar verme birimlerinin birbirleri ile kıyaslanması sonucu elde edilen etkinlik skorları aracılığıla bilgi edinilebilir. VZA'da, karar verme birimlerinin etkinlik düzeylerinin zaman içerisindeki değişimleri ortaya konamaz; VZA dinamik bir analiz değildir. Karar verme birimlerinin etkinlik düzeylerini belirlemek için bu birimlerin hem birbirleri ile karşılaştııılmaları, hem de zamana göre etkinlik değişimlerinin ortaya konulması amacıyla bu çalışmada MTFV'den de yararlanılmıştır. MTFV analizi sonuçlarına göre OECD ülkeleri arasında, 2015 yılıyla kıyaslandığında 2017 yılında Finlandiya, İtalya, Yunanistan, Macaristan, Hollanda, Slovenya, İspanya ve İsviçre etkinlik ilerlemesi göstermiștir. OECD ülkelerinin 2015 yılına kıyasla 2016 yılı MTFV değerlerine bakıldığında Avusturya, Belçika, Çek Cumhuriyeti, Finlandiya, Yunanistan, Macaristan, İsrail, İtalya, Hollanda, Polonya ve Slovenya'nın etkinlik ilerlemesi gösteren ülkeler olduğu belirlenmiștir. 2016 yılına kıyasla 2017 yılı MTFV değerleri incelendiğinde ise Finlandiya, İtalya, Fransa, İrlanda, Lüksemburg, Hollanda, Norveç, Slovenya, Slovakya, İspanya ve İsviçre'nin etkinlik ilerlemesi gösterdiği tespit edilmiştir. Üç dönemde de etkin bulunan ülkeler Finlandiya, İtalya, Hollanda ve Slovenya'dır.

Bu çalıșma uzun dönemli bakım hizmetlerinde etkinliğinin artırılmasında hangi değişkenlere nasıl odaklanılacağ konusunda önemli öneriler içermektedir. Çalışmada etkin bulunan ülkeler, etkin bulunmayan ve uzun dönemli bakım hizmetlerinde çalışmalar yapacak ülkeler için örnek olabilir. Son olarak yaşlılara veya uzun dönemli bakıma ihtiyaç duyan bireylere yönelik uzun dönemli bakım kalitesinde meydana gelen ilerlemeyi veya performansı, ölçmeden ve karşılaştırmadan bakım kalitesini izlemek veya iyileştirmek mümkün değildir. RAI gibi araçlar, bakımın kalitesi ve hizmet ihtiyaçlarına yönelik bilimsel açıdan önemli bilgiler sağlamaktadır. Ayrıca bu araçlar, bakım kalitesini ve bakım 
hizmetlerinin etkinliğini kıyaslamak için bakım planlaması ve bakım sağlama amacıyla kaydedilen bireysel düzeyde standartlaştırılmış veriler sunmaktadır. Standartlaştırılmış veriler sayesinde yapılacak karşılaştırmalar, kurumlar, bölgeler veya uluslararası politika ve uygulamaları inceleyerek sonuçlarda nasıl iyileştirmeler yapılacağını gösterebilecektir. Ayrıca bu tür araçların ülkeler tarafından kullanılması yüksek kalitede hizmet sunumunu ve performans verilerinin düzenli şekilde toplanmasını sağlayabilecektir.

\section{Kaynakça}

Abbasi, F., \& Hajihoseini H. (2004). Technological efficiency of R\&D units. In A. Emrouznejad \& V. Podinovski (Ed.), Data envelopment analysis and performance management. UK: Warwick Print.

Abdel-Rahman, N., Yoffe, N., Siman-Tov, M., Radovmislensky, I., \& Peleg, K. (2019). Achieving ethnic equality in the Israel trauma healthcare system: the case of the elderly population. Israel Journal of Health Policy Research, 8(1), 25.

Alamgir, H., Yu, S., Fast, C., Hennessy, S., Kidd, C., \& Yassi, A. (2008). Efficiency of overhead ceiling lifts in reducing musculoskeletal injury among carers working in long-term care institutions. Injury, 39(5), 570-577.

Anderson, G. F., \& Hussey, P. S. (2000). Population Aging: A Comparison Among Industrialized Countries: Populations around the world are growing older, but the trends are not cause for despair. Health Affairs, 19(3), 191-203.

Ayanoğlu, Y., Atan, M. \& Beylik, U. (2010). Hastanelerde veri zarflama analizi (VZA) yöntemiyle finansal performans ölçümü ve değerlendirilmesi. Să̆llkta Performans ve Kalite Dergisi, 2(2), 40-62.

Banker, R. D., Charnes, A., \& Cooper, W. W. (1984). Some Models for Estimating Technical and Scale Inefficiencies in Data Envelopment Analysis. Management Science, 30(9), 1078-1092.

Berta, W., Laporte, A., \& Kachan, N. (2010). Unpacking the relationship between operational efficiency and quality of care in Ontario long-term care homes. Canadian Journal on Aging/La Revue canadienne $d u$ vieillissement, 29(4), 543-556.

Björkgren, M. A., Häkkinen, U., \& Linna, M. (2001). Measuring efficiency of long-term care units in Finland. Health Care Management Science, 4(3), 193200.

Boles, J.S., Donthu N., \& Lohtia R. (1995). Salesperson Evaluation Using Relative Performance Efficiency: The Application of Data Envelopment Analysis. Journal of Personal Selling and Sales Management, 15(3), 31-49.

Caves, D. W., Christensen, L. R., \& Diewert, W. E. (1982a). The Economic Theory of Index Numbers and the Measuremnt of Input, Output, and Productivity. Econometrica, 50, 1393-1414.
Caves, D. W., Christensen, L. R., \& Diewert, W. E. (1982b). Multilateral Comparisons of Output, Input, and Productivity Using Superlative Index Numbers. The Economic Journal, 92, 73-86.

Charnes, A., Cooper, W., \& Rhodes, E. (1978). Measuring the Efficiency of Decision Making. European Journal of Operational Research, 2(6), 429-444.

Chern, J.Y., \& Wan T.T. (2000). The Iimpact of the Prospective Payment System on the Technical Efficiency of Hospitals. Journal of Medical Systems, 24, 159-172.

Chowdhury, H., Wodchis, W., \& Laporte, A. (2011). Efficiency and Technological Change in Health Care Services in Ontario: An Application of Malmquist Productivity Index with Bootstrapping. International Journal of Productivity and Performance Management, 60(7), 721-745.

Colombo, F., Llena-Nozal A., Mercier J., \& Tjadens F. (2011). Help Wanted?: Providing and Paying for LongTerm Care. Paris: OECD Publishing.

Deviren N.V., \& Duran T. (2018). Türkiye'de düzey 3 bölgesi kamu yatırımları etkinliğinin veri zarflama analizi (VZA) yöntemiyle ölçülmesi: Aydın, Denizli VE Muğla illeri örneği. Elektronik Sosyal Bilimler Dergisi, 17(65), 262-277.

Grifell-Tatje, E., \& Lovell, C. A. K. (1996). Deregulation and Productivity Decline: The Case of Spanish Savings Banks. European Economic Review, 40(6), 1281-1303.

Harris, J.M., Ozgen H., \& Ozcan Y.A. (2000). Do Mergers Enhance the Performance of Hospital Efficiency? Journal of Operations Research Society, 51, 801-811.

Hoff, A. (2006). Bootstrapping Malmquist Indices for Danish Seiners in the North Sea and Skagerrak. Journal of Applied Statistics, 33(9), 891-907.

Ingle, G. K., \& Nath, A. (2008). Geriatric health in India: Concerns and solutions. Indian Journal of Community Medicine: Official Publication of Indian Association of Preventive \& Social Medicine, 33(4), 214.

İnterRAI. (2019). Case-Mix Classification. (Erişim: 06/08/2019), https://www.interrai.org/classification.html

Koç Ş., \& Şahin M. (2018). Tobit model ve bir uygulama. KSÜ Doğa Bilimleri Dergisi, 21(1), 73-80.

Laine, J., Linna, M., Häkkinen, U., \& Noro, A. (2005). Measuring the productive efficiency and clinical quality of institutional long-term care for the elderly. Health Economics, 14(3), 245-256.

LaPlante, A.E. \& Paradi J.C. (2015). Evaluation of Bank Branch Growth Potential Using Data Envelopment Analysis. Omega, 52, 33-41.

Malmquist, S. (1953). Index numbers and indifference surfaces. Trabajos de Estadistica y de Investigacion Operativa, 4(2), 209-242.

Mardini, M. T., Iraqi, Y., \& Agoulmine, N. (2019). A Survey of Healthcare Monitoring Systems for Chronically Ill 
Patients and Elderly. Journal of Medical Systems, 43(3), 50 .

Moreno-Serra, R., \& Smith, P. (2012). An Exploratory Application of Data Envelopment Analysis to the Efficiency of Health Service Coverage And Access.(Erişim: 05/08/2019), https://www.r4d.org/wpcontent/uploads/THF-Efficiency-of-health-servicecoverage-and-access.pdf

Narc1, H. Ö. (2012). Sağlık Kurumlarında Verimlilik Ölçümü ve Yöntemleri. In İ. Şahin \& H.Ö. Narcı (Ed.), Sağlık Kurumlarında Operasyon Yönetimi. Eskişehir: T.C. Anadolu Üniversitesi Yayını.

OECD. (2015). Health at a Glance 2015: OECD Indicators. Paris: OECD Publishing.

OECD. (2017). Health at a Glance 2017: OECD Indicators. Paris: OECD Publishing.

OECD. (2019). Health Data. (Erişim: 07/08/2019), http://www.oecd.org/els/health-systems/healthdata.htm

OECD/European Commission. (2013). A Good Life in Old Age? Monitoring and Improving Quality in Long-term Care. OECD Publishing.

Ozbugday, F. C., Tirgil, A., \& Kose, E. G. (2019). Efficiency changes in long-term care in OECD countries: A nonparametric Malmquist Index approach. SocioEconomic Planning Sciences.

Özcan, Y. A., \& Khushalani, J. (2017). Assessing efficiency of public health and medical care provision in OECD countries after a decade of reform. Central European Journal of Operations Research, 25(2), 325-343.

Özcan, Y.A. (2014). Health Care Benchmarking and Performance Evaluation. USA: Springer.

Özgen, H., \& Özcan Y.A. (2004). Longitudinal Analysis of Efficiency in Multiple Output Dialysis Markets. Health Care Management Science, 7, 253-261.

Roh, C. Y., Park, C., \& Moon, M. J. (2011). Economic Performances of U.S. Non-profit Hospitals Using the Malmquist Productivity Change Index. Journal of Management and Marketing Research, 8(1), 1-16.

Samut, P.K., \& Cafri, R. (2016). Analysis of the Efficiency Determinants of Health Systems in OECD Countries by DEA and Panel Tobit. Social Indicators Research, 129, 113-132.
Sar1, Z. (2015). Veri Zarflama Analizi ve Bir Uygulama. Yüksek Lisans Tezi, Hacettepe Üniversitesi Fen Bilimleri Enstitüsü, Ankara.

Sherman, H. D. (1984). Data Envelopment Analysis as a New Manegerial Audit Methodology- Test and Evaluation. Auditing: A Journal of Practice and Theory, 4, 35-53.

Shimizutani, S., \& Suzuki, W. (2002). The quality and efficiency of at-home long-term care in Japan: Evidence from micro-level data. Economic and Social Research Institute (ESRI).

Sivakumar, P. T., Mukku, S. S. R., Antony, S., Harbishettar, V., Kumar, C. N., \& Math, S. B. (2019). Implications of Mental Healthcare Act 2017 for geriatric mental health care delivery: A critical appraisal. Indian Journal of Psychiatry, 61(4), 763.

Smith, P. C., Mossialos, E., Leatherman, S., \& Papanicolas, I. (2009). Performance measurement for health system improvement: experiences, challenges and prospects. Cambridge University Press.

Spillman, B. C., \& Lubitz, J. (2000). The effect of longevity on spending for acute and long-term care. New England Journal of Medicine, 342(19), 1409-1415.

Spinks, J. \& Hollingsworth, B. (2009). Cross-Country Comparisons of Technical Efficiency of Health Production: A Demonstration of Pitfalls. Applied Economics, 41(4), 417-427.

Şahin, İ. (2008). Sağlık Bakanlığı Genel Hastaneleri ve Sağlık Bakanlığına Devredilen SSK Genel Hastanelerinin Teknik Verimliliklerinin Karşılaştırmalı Analizi. Hacettepe Sağlık İdaresi Dergisi, 11(1), 1-48.

Tobin J. (1958). Estimation of relationships for limited dependent variables. Econometrica, Journal of Econometric Society, 26(1), 24-36.

Vassiloglou, M., \& Giokas, D. (1990). A study of the relative efficiency of bank branches: an application of data envelopment analysis. Journal of the Operational Research Society, 41(7), 591-597.

Wichmann, A. B., Adang, E. M., Vissers, K. C., Szczerbińska, K., Kylänen, M., Payne, S., vd. (2018). Technical-efficiency analysis of end-of-life care in long-term care facilities within Europe: A crosssectional study of deceased residents in $6 \mathrm{EU}$ countries (PACE). PloS One, 13(11), 1-12. 